Original Research

\title{
An evaluation on changes in Hippocampus size for Cognitively Normal (CN), Mild Cognitive Impairment (MCl), and Alzheimer's disease (AD) patients using Fuzzy Membership Function
}

\author{
Ruhul Amin Hazarika ${ }^{1}$, Arnab Kumar Maji ${ }^{*}$, Debdatta Kandar ${ }^{1}$, Prasun Chakrabarti2 ${ }^{2}$ Tulika \\ Chakrabarti3 ${ }^{3}$ KS Jagannatha Rao ${ }^{4}$, Jose Carvalho5, Babak Kateb6, Mohammad Nami4,5,7,8*
}

\author{
${ }^{1}$ Department of Information Technology, North Eastern Hill University, Shillong, Meghalaya, India \\ 2Techno India NJR Institute of Technology, Udaipur, Rajasthan, India \\ 3Sir Padampat Singhania University, Udaipur, Rajasthan, India \\ ${ }^{4}$ Neuroscience Center, Instituto de Investigaciones Científicas y Servicios de Alta Tecnología (INDICASAT AIP), City of \\ Knowledge, Panama City, Panama \\ 5 High Performance Brain, Rotterdam, Netherlands \\ ${ }^{6}$ Director, National Center for NanoBioElectoronics; Director, Brain Technology and Innovation Park; President, \\ Brain Mapping Foundation; Chairman and CEO, Society for brain mapping and Therapeutics and, Chairman of \\ Neuroscience20-G20 summit, Los Angeles, CA, USA \\ ${ }^{7}$ Department of Neuroscience, School of Advanced Medical Sciences and Technologies, Shiraz University of Medical \\ Sciences; DANA Brain Health Institute, Iranian Neuroscience Society-Fars Chapter, Shiraz, Iran \\ 8Inclusive Brain Health, Swiss Alternative Medicine, Geneva, Switzerland \\ *Corresponding Authors \\ Arnab Kumar Maji PhD, Department of Information Technology, North Eastern Hill University, Shillong, Meghalaya, India, Email: \\ arnab.maji@gmail.com; Mohammad Nami MD, PhD, Department of Neuroscience, School of Advanced Medical Sciences and \\ Technologies, Shiraz University of Medical Sciences, Shiraz-7134814336- Iran, Email: torabinami@sums.ac.ir
}

\begin{abstract}
Background: Alzheimer's disease (AD) is a neurological disorder where the hippocampus in the brain gets affected severely. Hippocampus is a part of the limbic system, which is mainly responsible for forming memories. The transition from Cognitively Normal (CN) to $A D$ is having one intermittent stage, popularly known as Mild Cognitive Impairment (MCl). In this study, segmentation operation has been performed first to separate the hippocampus, and then an analysis has been made on the basis of changes in area and atrophy in the hippocampus. A total of "2008" numbers of MR images have been analyzed for three different subject groups consist of "210" different subjects (Male:105, Female: 105) namely, CN, MCl, and AD.

Objective: The objective of this study is to analyze the size and atrophy of the hippocampus due to AD and $\mathrm{MCl}$ in comparison with $\mathrm{CN}$ patients.

Material and Methods: All the experiments have done using MATLAB tools. All the data used is acquired from the online dataset "Alzheimer's Disease Neuroimaging Initiative (ADNI)".

Results: From the study, it is found that the average difference in the size of the hippocampus between CN and $\mathrm{MCl}$ is $17.05 \%$, between $\mathrm{CN}$ and $\mathrm{AD}$ is $31.90 \%$, and between $\mathrm{MCl}$ and $\mathrm{AD}$ is $18.24 \%$. The average atrophy per year in the hippocampus is found to be as $4.62 \%$ for $\mathrm{AD}, 2.33 \%$ for $\mathrm{MCl}$, and $1.10 \%$ for $\mathrm{CN}$ subjects.

Conclusions: From the study, it is observed that, for AD patients, hippocampus atrophy is highest, and hence they experience the highest memory loss followed by the $\mathrm{MCl}$ and $\mathrm{CN}$ patients.
\end{abstract}

Keywords: Alzheimer's Disease (AD), Mild Cognitive Impairment (MCl), Hippocampus, Segmentation, Atrophy, Magnetic Resonance Imaging (MRI), Cognitively Normal (CN) 


\section{INTRODUCTION}

Alzheimer's disease (AD): AD is a progressive brain disorder caused by the damages of brain cells, which leads to memory loss and a decline of intellectual ability [1] [2]. According to the research report by the National Institute on Aging, about 6 million people from the U.S.A, aged about 60-70 are suffering from $A D$ [3]. In the U.S.A, AD is ranked as the sixth major cause of death for older people, which may reach the third rank in the coming years [3]. According to the report of Alzheimer's and Dementia Resources, in India, more than 4 million people have some form of dementia including AD. Worldwide, at least 44 million people are living with dementia [4].

Mild Cognitive Impairment $(\mathrm{MCl})$ : $\mathrm{MCl}$ is an intermediate stage when a person is considered to be in between $\mathrm{CN}$ and $\mathrm{AD}$ [5]. Although the symptoms of a person having $\mathrm{MCl}$ are not as serious as having $A D$, they experience memory loss more than the normal people of their age [6]. According to the researchers, although all people with $\mathrm{MCl}$ may not develop $A D$, but patients with $\mathrm{MCl}$ develop $A D$ faster than CN people [7]. According to a research article by Matthew Davis, et al., the approximate probability to develop AD by the $\mathrm{MCl}$ subjects is around $22 \%$ [8].

In most neuropsychiatric disorders including $A D$ and $\mathrm{MCl}$, the hippocampus is one of the severely affected areas in the brain [9]. Hippocampus is a small, curved, complex structure in the brain that plays a significant role in regulating emotional responses, forming memories and navigation, etc. [10]. Hippocampus is also an important part of the limbic system, located in the medial region of the temporal lobe. The damage of the hippocampus causes amnesia [11] and incapable of forming new memories, especially related to time as well as the location [12].

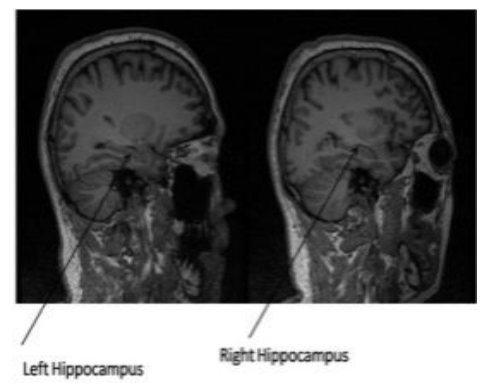

Figure 1. Left and Right Hippocampus of a male, $\mathrm{CN}$ subject at the age of 60

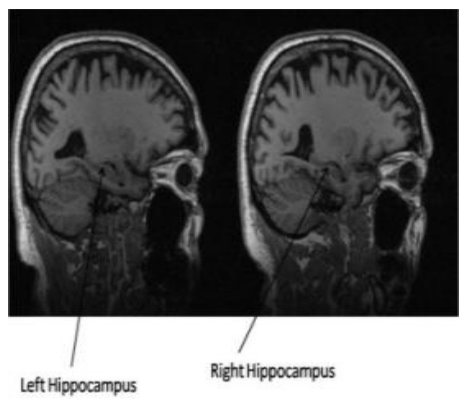

Figure 2. Left and Right Hippocampus of a male, $\mathrm{MCl}$ subject at the age of 60

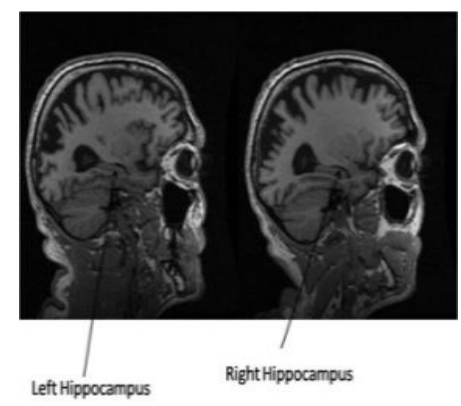

Figure 3. Left and Right Hippocampus of a male, AD subject at the age of 60 
Although the decay in the hippocampus occurs over the ages, the rate of hippocampal atrophy in $\mathrm{AD}$ and $\mathrm{MCl}$ is higher than of normal aging [13]. According to a research [14], the average difference in the size of the hippocampus between $A D$ and $\mathrm{CN}$ patients is $32 \%$, between $\mathrm{MCl}$ and $\mathrm{CN}$ patients is $19 \%$ and between $\mathrm{MCl}$ and $\mathrm{AD}$ patients is $15 \%$. According to some other researchers, the average hippocampal atrophy in $\mathrm{AD}$ is between $20 \%$ and $52 \%$ compared to $\mathrm{CN}$ patients [15], and the average hippocampal atrophy in $\mathrm{AD}$ is between $16 \%$ and $27 \%$ compared to the $\mathrm{MCl}$ patients [16]. According to research, the rate of atrophy in hippocampus volume is greater in $\mathrm{AD}$ subjects followed by the $\mathrm{MCl}$ and then the $\mathrm{CN}$ subjects [13]. According to research [17], the annual atrophy in the hippocampus is $1.4 \%$ for $\mathrm{CN}$ subjects and $4.6 \%$ for $\mathrm{AD}$ subjects. According to another literature [18], the hippocampus atrophy per year for $\mathrm{MCl}$ patients is $2.53 \%$, whereas $1.12 \%$ for $\mathrm{CN}$ patients. In figure 1 to figure 3 , a sample brain MR image containing the left and right hippocampus is shown for $A D, M C l$, and $C N$ subjects.

Although many researchers have done similar works, they have not performed the comparison according to the subject's age and gender. In this paper, we have performed the comparison separately for different aged groups for both male and female subjects.

\section{RELATED WORKS}

AD causes damage in the hippocampus cells [19]. Many researchers have been doing research on the size as well as the atrophy of the hippocampus in the human brain. A few of the related research works are described below.

Henneman, W. J. P., et al. [20], have done research work with a total number of $64 \mathrm{AD}, 44 \mathrm{MCl}$, and $34 \mathrm{CN}$ subjects. The coronal three-dimensional T1-weighted gradient-echo sequence data are acquired from the 1.0 Tesla (Siemens Magnetom Impact Expert System, Siemens AG, Erlangen, Germany). The authors have used the Show Images 3.7.0 software package for selecting and segmenting the Region of Interest (ROI). The Structural Image Evaluation, using Normalization, of Atrophy, Cross-sectional (SIENAX), and Structural Image Evaluation, using Normalization, of Atrophy (SIENA), both are the part of FMRIB's Software Library are used to calculate the hippocampal volumetric changes per year. The authors have concluded that the hippocampus atrophy for the $\mathrm{CN}$ subjects is around $2.2 \%$, for the $\mathrm{MCl}$ subjects' atrophy is around $3.8 \%$, and for AD subjects the atrophy is around $4.0 \%$.

Seab, J. P., et al. [21], have done research work in a related field. The authors have acquired 10 AD subjects and $7 \mathrm{CN}$ subjects for the study. However, the authors have not mentioned any information about the dataset they have used. The study is done using the IBM/MIT/LBL 0.5-T NMR imager software. After selecting the ROI, considered the hippocampus as an elliptical shape, and calculated the volume of the ROI over the years. Finally, the authors have concluded that an AD patient experiences a loss of around $40 \%$ of the hippocampal volume in his/her lifetime than of a normal subject.

Similar research has been done by Liedes, Hilkka, et al. [22]. The authors have acquired the MRI data from Alzheimer's disease Neuroimaging Initiative (ADNI 1) and the Australian Imaging Biomarkers and Lifestyle Flagship Study of Ageing (AIBL) databases. The authors have used the Tensor-Based Morphometry (TBM), and Voxel-Based Morphometry (VBM) is used to extract the features from the baseline MRI. Hippocampal volume change is determined by observing the changes that occurred in the intensity levels of the hippocampus using the Extended Boundary Shift Integral (eBSI) method. According to the authors, the annual atrophy in the hippocampus for the $\mathrm{CN}$ subjects is around $(1.17 \pm 1.11) \%$, for Stable $\mathrm{MCl}(\mathrm{SMCl})$ subjects the annual atrophy in the hippocampus is around $(2.47 \pm 2.30) \%$, for Progressive $\mathrm{MCl}(\mathrm{PMCl})$ subjects the atrophy in the hippocampus is around $(4.43 \pm 2.36) \%$, and for the $\mathrm{AD}$ subjects the annual atrophy in the hippocampus is around $(5.84 \pm 2.97) \%$.

Uysal, Gokce, and Mahmut Ozturk proposed a novel approach [23] for the classification of AD based on the hippocampus volume. The T1-weighted MRI data are acquired from the ADNI data set. The hippocampal volumetric information is obtained by using a semi-automatic separation software ITKSNAP. The borders of both the hippocampus are determined and labeled by the software in order to segment it accurately. According to the research, the average size of the left hippocampus in AD is approximately $26 \%$ smaller than $\mathrm{MCl}$, and $42 \%$ smaller than $\mathrm{CN}$ subjects, whereas the average size of the right hippocampus in $\mathrm{AD}$ is approximately $24 \%$ smaller than $\mathrm{MCl}$, and $39 \%$ smaller than $\mathrm{CN}$ 
subjects. The average size in the left hippocampus in $\mathrm{MCl}$ is approximately $20 \%$ smaller than $\mathrm{CN}$, and the average size of the right hippocampus in $\mathrm{MCl}$ is approximately $20 \%$ smaller than $\mathrm{CN}$ subjects.

Research on hippocampal atrophy in $\mathrm{AD}$, and $\mathrm{MCl}$ subjects have done by Mueller, Susanne G., et al. [24]. For the study, the authors have acquired 91 T-2 weighted MR images. From the input images, the ROIs (i.e, the hippocampus) is manually selected and segmented by using the FreeSurfer software. Multiple-Linear-Regression (MLR) analyses through the subfields, correspondingly hippocampus volume, as well as the Intracranial Volume (ICV) as autonomous variables are used for identifying the volumes. According to the authors, the average size of the hippocampus in AD is approximately $10 \%$ smaller than $\mathrm{MCl}$, and $16 \%$ smaller than $\mathrm{CN}$ subjects. The average size of the hippocampus in $\mathrm{MCl}$ is approximately $7 \%$ smaller than $\mathrm{CN}$ subjects.

A related work has done by Wang, D., et al. [25]. The authors have acquired the data from $20 \mathrm{aMCl}$, $20 \mathrm{AD}$ and 20 normal controls subjects. The authors have concluded that there is a significant hippocampal volumetric difference between $\mathrm{NC}, \mathrm{MCl}$, and $\mathrm{AD}$ subjects. However, the number of subjects (60) for the study is relatively small. Moreover, the authors have not performed any volumetric comparison among the subject groups.

\section{MATERIAL AND METHODS}

\subsection{PREPROCESSING}

Since after the segmentation of 3D MRI, some post-processing steps are required to be performed, which may be time-consuming, most of the researchers prefer to segment the MRI on 2D images [26]. In our work, we have converted the 3D MR images to 2D for the particular slice where the hippocampus is located. All the images are resized to $256 \times 256$ pixels.

The brain MR images also contain some unwanted pixels, which are also known as the skull [27]. For accurate segmentation of a region in the brain, it is necessary to strip the skull part from the MR images [28]. After comparing the performance of five popular segmentation techniques namely Region-growing [29], Region splitting \& Merging [30], K - Means algorithm [31], Histogram-based algorithm [32], and Fuzzy C Means [33] for 50 MRI images, it is found that the Histogram Based Thresholding technique gives the highest accuracy among all these algorithms [34]. Hence, for skull stripping, we have used the Histogram Based Thresholding technique. Python tool is used for skull stripping. In figure 4, a sample input image, and in figure 5, the corresponding skull stripped output image is shown.

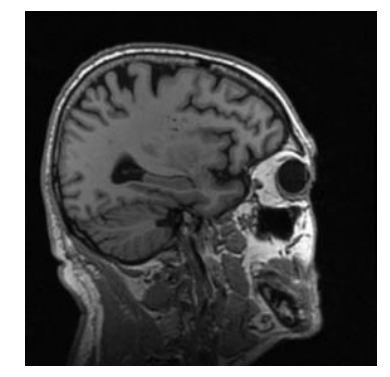

Figure 4. Input MRI with skull

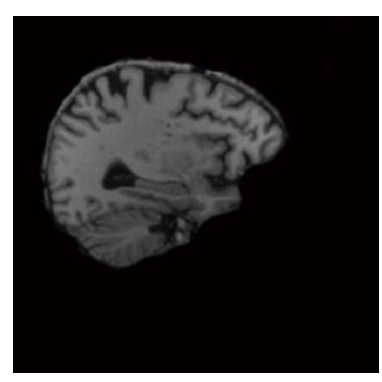

Figure 5. Output image, after removing the skull using Histogram based Thresholding technique 


\subsection{HIPPOCAMPUS SEGMENTATION}

Segmentation is an operation to separate the important parts from an object [35]. Segmentation of the hippocampus from the brain is very important in order to study the changes that occur in different neurological disorders like AD, $\mathrm{MCl}$, etc [36] [37]. Although many researchers have proposed different hippocampus segmentation techniques, accurate hippocampus segmentation is still considered as a challenge for the researchers [38]. Matrix Laboratory (MATLAB) is a well-known tool in the area of medical image processing, including the segmentation of medical images [39]. For analyzing the hippocampus size for different subject groups, we have segmented the hippocampus using MATLAB tool.
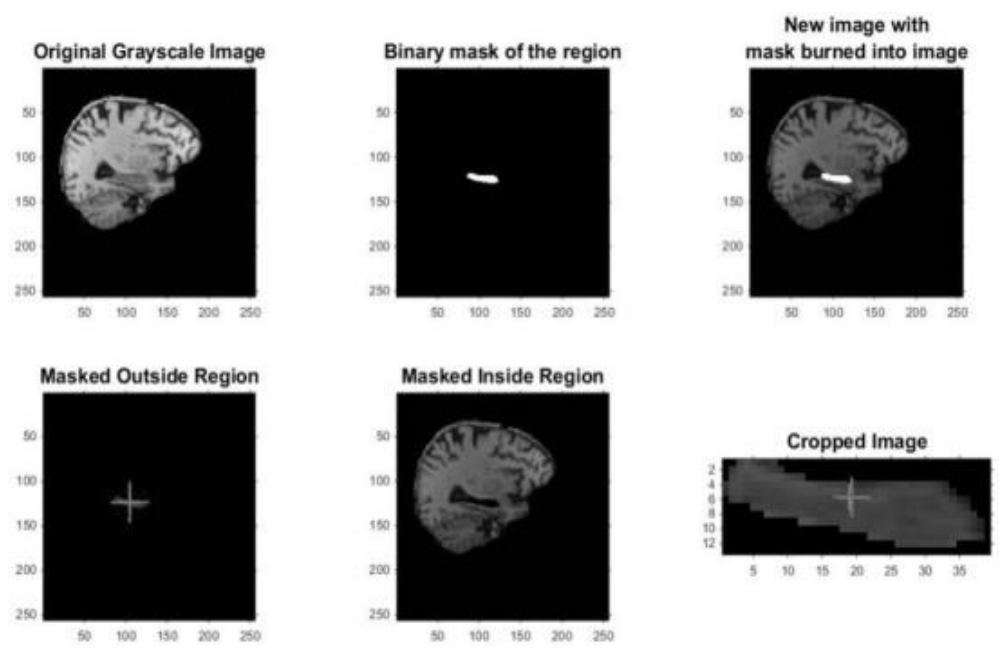

Figure 6. Segmentation of hippocampus from brain MRI using MATLAB tool

All skull stripped MR images are resized to $256 \times 256$ pixels and used as input images. From the input images, Region of interest (ROI), i.e., the hippocampus is selected and segmented automatically by the MATLAB tool as shown in fig 6 . The shape of the hippocampus can be related to the shape of an ellipse [40]. The average accuracy for the hippocampus segmentation is determined with their corresponding ground truth images and found to be approximately $97 \%$. To analyze the size of the segmented hippocampus, the following algorithm is used:

Step 1: Determine the number of pixels in the major axis of the segmented area, N1.

Step 2: Calculate the number of pixels in major radius, $m 1=(N \div 2)$.

Step 3: Determine the number of pixels in the minor axis of the segmented area, N2.

Step 4: Calculate the number of pixels in minor radius, $m 2=(\mathrm{N} 2 \div 2)$.

Step 5: Convert the number of pixels in $\mathrm{m} 1$ and $\mathrm{m} 2$ to the size in "mm", by using the following formula:

$$
\begin{aligned}
& r 1=(25.4 \div D) \times m 1 \\
& r 2=(25.4 \div D) \times m 2
\end{aligned}
$$

Where, $D=$ Dot per Inch (DPI) of the image, which is 96 for all the input images considered in this work.

Step 6: Calculate the approximate area of the segmented region by using the following formula:

$$
a=\pi \times r 1 \times r 2
$$


A sample hippocampus segmentation using the binary mask is shown in Figure 6.

\section{RESULTS AND DISCUSSION}

A total of "2008" numbers of brain MR images for "210" numbers of different subjects are acquired from the ADNI dataset. After segmenting the hippocampus (both left and right), we have analyzed the size and the average atrophy for $\mathrm{CN}, \mathrm{MCl}$, and $\mathrm{AD}$ subjects (male/female) of different aged groups (i.e., 60-64 years, 65-69 years, 70-74 years, 75-79 years, 80-84 years, and 85-90 years). The difference in hippocampus size among $\mathrm{CN}, \mathrm{MCl}$, and $\mathrm{AD}$ subjects are shown in table 1 to table 3 . The average atrophy in hippocampus size among $\mathrm{CN}, \mathrm{MCl}$, and $\mathrm{AD}$ subjects are presented in table 4 to table 6 .

Table 1. Difference in hippocampus size of $\mathrm{CN}$ vs. $\mathrm{MCl}$ subjects

\begin{tabular}{|c|c|c|c|c|c|c|c|}
\hline \multirow[t]{2}{*}{ Sex } & \multirow[t]{2}{*}{ Age } & \multicolumn{6}{|c|}{$\begin{array}{l}\text { Difference in hippocampus size of Average difference in hippocampus size of } \\
\mathrm{CN} \text { vs. } \mathrm{MCl} \text { Subjects } \\
\mathrm{CN} \text { vs. } \mathrm{MCl} \text { Subjects }\end{array}$} \\
\hline & & Left & Right & Total & Left & Right & Total \\
\hline \multirow{6}{*}{ M } & $60-64$ & $18.48 \%$ & $17.52 \%$ & $18.00 \%$ & \multirow{6}{*}{$17.27 \%$} & \multirow{6}{*}{$17.42 \%$} & \multirow{6}{*}{$17.34 \%$} \\
\hline & $65-69$ & $23.62 \%$ & $24.79 \%$ & $24.21 \%$ & & & \\
\hline & $70-74$ & $21.14 \%$ & $22.12 \%$ & $21.64 \%$ & & & \\
\hline & 75-79 & $13.54 \%$ & $13.45 \%$ & $13.49 \%$ & & & \\
\hline & $80-84$ & $11.39 \%$ & $9.76 \%$ & $10.55 \%$ & & & \\
\hline & $85-90$ & $15.43 \%$ & $16.86 \%$ & $16.15 \%$ & & & \\
\hline \multirow{6}{*}{$F$} & $60-64$ & $15.53 \%$ & $15.44 \%$ & $15.48 \%$ & \multirow{6}{*}{$16.79 \%$} & \multirow{6}{*}{$16.73 \%$} & \multirow{6}{*}{$16.76 \%$} \\
\hline & $65-69$ & $18.35 \%$ & $18.50 \%$ & $18.43 \%$ & & & \\
\hline & $70-74$ & $14.69 \%$ & $14.54 \%$ & $14.62 \%$ & & & \\
\hline & $75-79$ & $17.99 \%$ & $17.16 \%$ & $17.57 \%$ & & & \\
\hline & $80-84$ & $16.62 \%$ & $17.27 \%$ & $16.94 \%$ & & & \\
\hline & $85-90$ & $17.58 \%$ & $17.46 \%$ & $17.52 \%$ & & & \\
\hline
\end{tabular}

Table 2. Difference in hippocampus size of $C N$ vs. AD subjects

\begin{tabular}{|c|c|c|c|c|c|c|c|}
\hline \multirow[t]{2}{*}{ Sex } & \multirow[t]{2}{*}{ Age } & \multicolumn{3}{|c|}{$\begin{array}{l}\text { Difference in hippocampus size of } \\
\text { CN vs. AD Subjects }\end{array}$} & \multicolumn{3}{|c|}{$\begin{array}{l}\text { Average difference in hippocampus size of } \\
\text { CN vs. AD Subjects }\end{array}$} \\
\hline & & Left & Right & Total & Left & Right & Total \\
\hline \multirow{6}{*}{ M } & $60-64$ & $32.12 \%$ & $32.34 \%$ & $32.23 \%$ & \multirow{6}{*}{$32.37 \%$} & \multirow{6}{*}{$32.87 \%$} & \multirow{6}{*}{$32.63 \%$} \\
\hline & 65-69 & $33.49 \%$ & $33.59 \%$ & $33.54 \%$ & & & \\
\hline & $70-74$ & 33.69\% & $34.36 \%$ & $34.03 \%$ & & & \\
\hline & $75-79$ & $33.41 \%$ & $31.71 \%$ & $32.56 \%$ & & & \\
\hline & $80-84$ & $29.15 \%$ & $31.84 \%$ & $30.53 \%$ & & & \\
\hline & $85-90$ & $32.33 \%$ & $33.41 \%$ & $32.87 \%$ & & & \\
\hline \multirow{6}{*}{$\mathrm{F}$} & $60-64$ & $23.29 \%$ & $23.37 \%$ & 23.33\% & \multirow{6}{*}{$30.81 \%$} & \multirow{6}{*}{$31.53 \%$} & \multirow{6}{*}{$31.18 \%$} \\
\hline & 65-69 & $31.01 \%$ & $34.15 \%$ & $32.62 \%$ & & & \\
\hline & $70-74$ & $30.51 \%$ & $31.98 \%$ & $31.26 \%$ & & & \\
\hline & 75-79 & $32.90 \%$ & $33.06 \%$ & $32.98 \%$ & & & \\
\hline & $80-84$ & $29.77 \%$ & $28.41 \%$ & $29.10 \%$ & & & \\
\hline & $85-90$ & $37.39 \%$ & $38.18 \%$ & $37.79 \%$ & & & \\
\hline
\end{tabular}


Table 3. Difference in hippocampus size of $\mathrm{MCl}$ vs. AD subjects

\begin{tabular}{|c|c|c|c|c|c|c|c|}
\hline \multirow[t]{2}{*}{ Sex } & \multirow[t]{2}{*}{ Age } & \multicolumn{6}{|c|}{$\begin{array}{l}\text { Difference in hippocampus size of Average difference in hippocampus size of } \\
\mathrm{MCl} \text { vs. AD Subjects } \\
\mathrm{MCl} \text { vs. AD Subjects }\end{array}$} \\
\hline & & Left & Right & Total & Left & Right & Total \\
\hline \multirow{6}{*}{ M } & $60-64$ & $16.73 \%$ & $17.96 \%$ & $17.35 \%$ & \multirow{6}{*}{$18.10 \%$} & \multirow{6}{*}{$18.48 \%$} & \multirow{6}{*}{$18.30 \%$} \\
\hline & $65-69$ & $12.92 \%$ & $11.71 \%$ & $12.32 \%$ & & & \\
\hline & $70-74$ & $15.92 \%$ & $15.73 \%$ & $15.82 \%$ & & & \\
\hline & 75-79 & $22.98 \%$ & $21.10 \%$ & $22.04 \%$ & & & \\
\hline & $80-84$ & $20.04 \%$ & $24.46 \%$ & $22.34 \%$ & & & \\
\hline & $85-90$ & $19.99 \%$ & $19.90 \%$ & $19.94 \%$ & & & \\
\hline \multirow{6}{*}{$\mathrm{F}$} & $60-64$ & $14.24 \%$ & $14.39 \%$ & $14.32 \%$ & \multirow{6}{*}{$17.71 \%$} & \multirow{6}{*}{$18.63 \%$} & \multirow{6}{*}{$18.18 \%$} \\
\hline & $65-69$ & $15.50 \%$ & $19.20 \%$ & $17.39 \%$ & & & \\
\hline & 70-74 & $18.55 \%$ & $20.41 \%$ & $19.49 \%$ & & & \\
\hline & 75-79 & $18.18 \%$ & $19.20 \%$ & $18.69 \%$ & & & \\
\hline & $80-84$ & $15.77 \%$ & $13.47 \%$ & $14.63 \%$ & & & \\
\hline & $85-90$ & $24.03 \%$ & $25.10 \%$ & $24.58 \%$ & & & \\
\hline
\end{tabular}

Table 4. Average atrophy in hippocampus for $\mathrm{CN}$ subjects

\begin{tabular}{|c|c|c|c|}
\hline \multirow[b]{2}{*}{ Sex } & \multirow[b]{2}{*}{ Age duration } & \multicolumn{2}{|l|}{ Subjects: CN } \\
\hline & & Total atrophy in hippocampus & $\begin{array}{l}\text { Average atrophy } \\
\text { per year in hippocampus }\end{array}$ \\
\hline \multirow{6}{*}{ M } & $60-64$ & $3.50 \%$ & \multirow{6}{*}{$1.09 \%$} \\
\hline & $65-69$ & $3.98 \%$ & \\
\hline & $70-74$ & $5.06 \%$ & \\
\hline & $75-79$ & $5.45 \%$ & \\
\hline & $80-84$ & $6.53 \%$ & \\
\hline & $85-90$ & $7.34 \%$ & \\
\hline \multirow{6}{*}{$\mathrm{F}$} & $60-64$ & $4.55 \%$ & \multirow{6}{*}{$1.11 \%$} \\
\hline & $65-69$ & $4.09 \%$ & \\
\hline & $70-74$ & $4.57 \%$ & \\
\hline & $75-79$ & $5.56 \%$ & \\
\hline & $80-84$ & $6.20 \%$ & \\
\hline & $85-90$ & $8.46 \%$ & \\
\hline
\end{tabular}


Table 5. Average atrophy in hippocampus for $\mathrm{MCl}$ subjects

\begin{tabular}{|c|c|c|c|}
\hline \multirow[b]{2}{*}{ Sex } & \multirow[b]{2}{*}{ Age duration } & \multicolumn{2}{|l|}{ Subjects: $\mathrm{MCl}$} \\
\hline & & Total atrophy in hippocampus & $\begin{array}{l}\text { Average atrophy } \\
\text { per year in hippocampus }\end{array}$ \\
\hline \multirow{6}{*}{ M } & $60-64$ & $9.80 \%$ & \multirow{6}{*}{$2.32 \%$} \\
\hline & $65-69$ & $11.14 \%$ & \\
\hline & $70-74$ & $14.00 \%$ & \\
\hline & $75-79$ & $10.51 \%$ & \\
\hline & $80-84$ & $12.25 \%$ & \\
\hline & $85-90$ & $11.90 \%$ & \\
\hline \multirow{6}{*}{$\mathrm{F}$} & $60-64$ & $10.67 \%$ & \multirow{6}{*}{$2.34 \%$} \\
\hline & $65-69$ & $10.05 \%$ & \\
\hline & $70-74$ & $12.28 \%$ & \\
\hline & $75-79$ & $10.67 \%$ & \\
\hline & $80-84$ & $13.33 \%$ & \\
\hline & $85-90$ & $13.25 \%$ & \\
\hline
\end{tabular}

Table 6. Average atrophy in hippocampus for AD subjects

\begin{tabular}{|c|c|c|c|}
\hline \multirow[b]{2}{*}{ Sex } & \multirow[b]{2}{*}{ Age duration } & \multicolumn{2}{|l|}{ Subjects: AD } \\
\hline & & Total atrophy in hippocampus & $\begin{array}{l}\text { Average atrophy } \\
\text { per year in hippocampus }\end{array}$ \\
\hline \multirow{6}{*}{ M } & $60-64$ & $22.13 \%$ & \multirow{6}{*}{$4.70 \%$} \\
\hline & $65-69$ & $18.29 \%$ & \\
\hline & $70-74$ & $20.78 \%$ & \\
\hline & $75-79$ & $27.96 \%$ & \\
\hline & $80-84$ & $24.90 \%$ & \\
\hline & $85-90$ & $26.96 \%$ & \\
\hline \multirow{6}{*}{$\mathrm{F}$} & $60-64$ & $22.26 \%$ & \multirow{6}{*}{$4.54 \%$} \\
\hline & $65-69$ & $20.77 \%$ & \\
\hline & $70-74$ & $20.05 \%$ & \\
\hline & $75-79$ & $23.35 \%$ & \\
\hline & $80-84$ & $23.43 \%$ & \\
\hline & $85-90$ & $26.37 \%$ & \\
\hline
\end{tabular}

The average hippocampus (left and right) size and the average hippocampal atrophy per year of all the subjects (male and female) are shown graphically in figure 7 to figure 10. 
Average hippocampus (left+right) size of $\mathrm{CN}, \mathrm{MCl}$, and $\mathrm{AD}$ subjects (male)

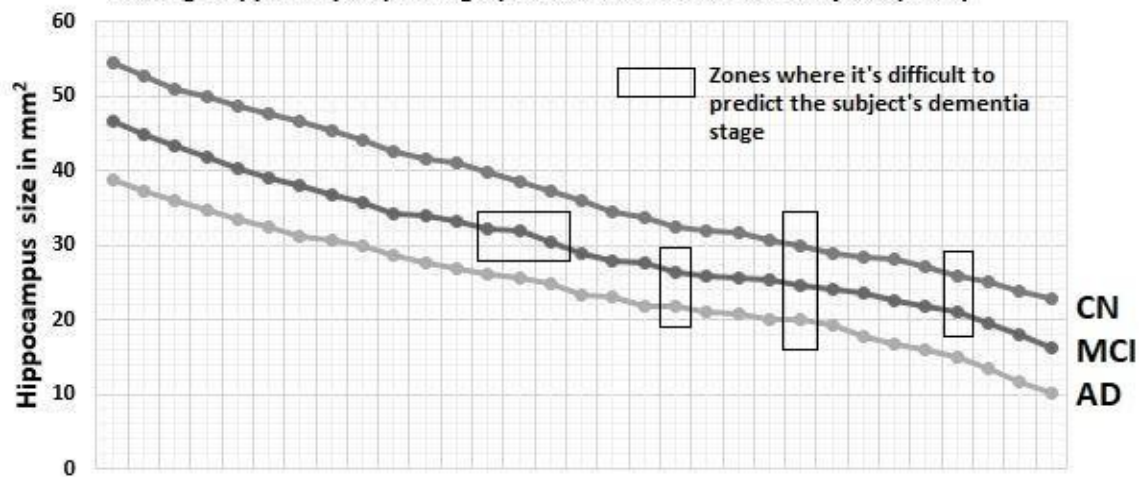

60616263646566676869707172737475767778798081828384858687888990

\section{Subject's age in years}

Figure 7. Average size of the hippocampus for $\mathrm{CN}, \mathrm{MCl}$, and $\mathrm{AD}$ male subjects

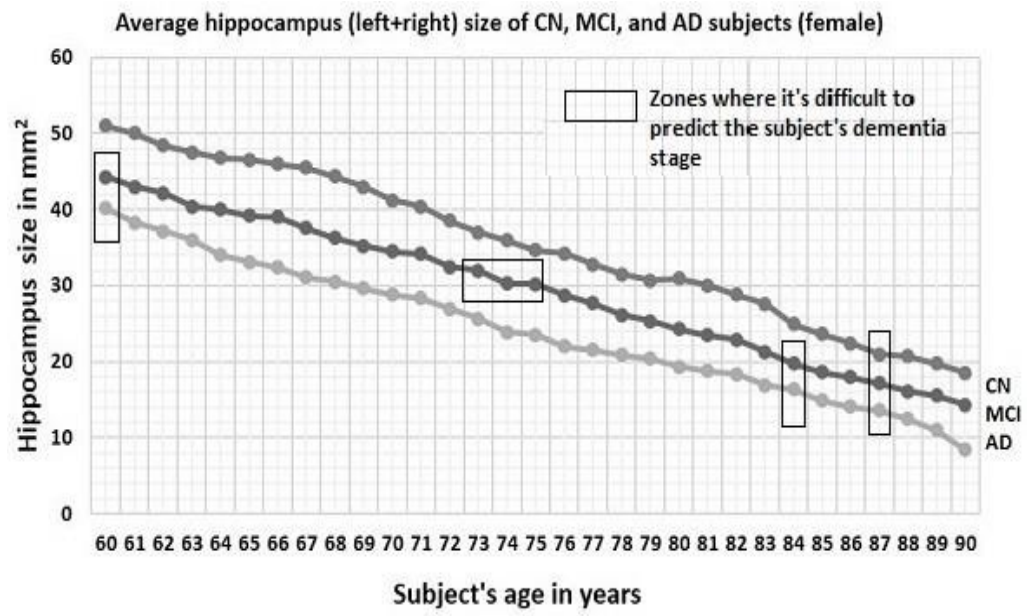

Figure 8. Average size of the hippocampus for $\mathrm{CN}, \mathrm{MCl}$, and $\mathrm{AD}$ female subjects

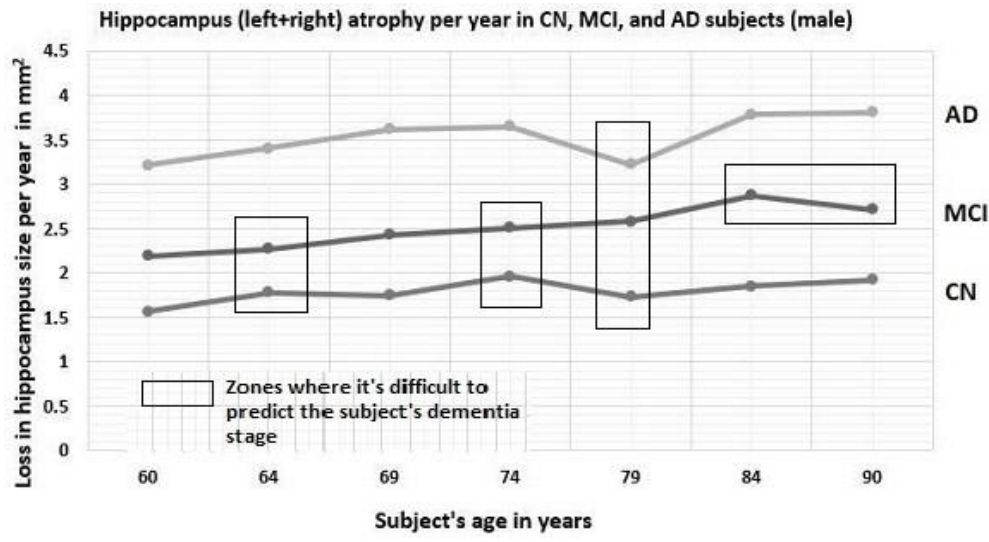

Figure 9. Average atrophy per year in hippocampus for $\mathrm{CN}, \mathrm{MCl}$, and $\mathrm{AD}$ male subjects 


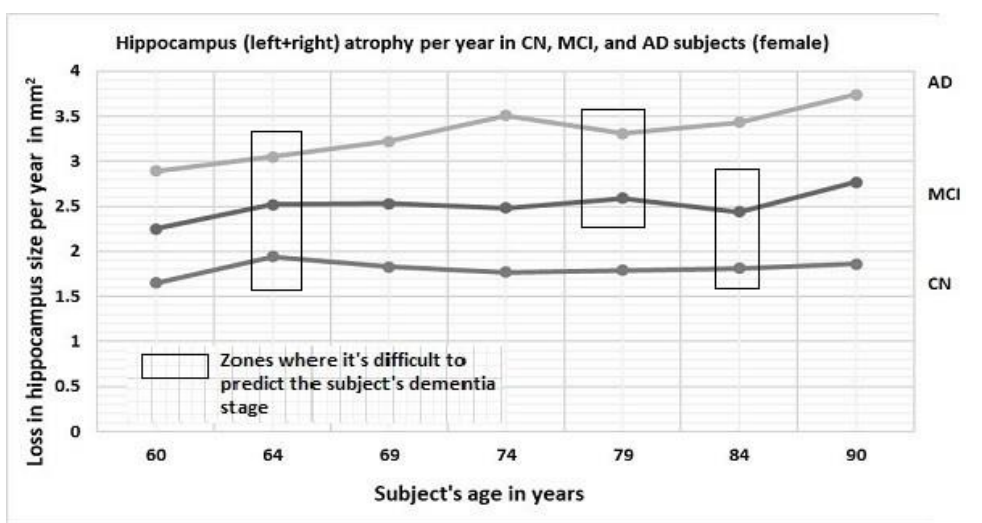

Figure 10. Average atrophy per year in hippocampus for $\mathrm{CN}, \mathrm{MCl}$, and $\mathrm{AD}$ female subjects

From figure 7 and figure 8, we can observe how the hippocampus size varies over the ages in CN, $\mathrm{MCl}$, and AD subjects (male and female). We can also observe that for some points in the x-axis (subjects age), the hippocampus size is almost identical or very near to each other.

By following up on the hippocampus size of the same subject for more than 2 consecutive years, we have analyzed the size of hippocampus loss per year, which is also known as the hippocampal atrophy rate. The average hippocampal atrophy per year for $\mathrm{CN}, \mathrm{MCl}$, and $\mathrm{AD}$ subjects are shown graphically in figure 9 and figure 10. From figure 9 and figure 10, in some points, the atrophy curve is

Figure 10: Average atrophy per year in hippocampus for CN, MCI, and AD female subjects almost identical for $\mathrm{CN}, \mathrm{MCl}$, and $\mathrm{AD}$ subjects (male and female).

It can be concluded from figure 7 to figure 10, if a subject's age and hippocampus size or hippocampal atrophy per year is known, from the graphs, sometimes it may be a challenge to decide the subject's stage (CN/MCl/AD). There are some zones in the graphs, which are marked by a rectangular shape, where it is very difficult to determine the subject's dementia stage (CN/MCl/AD). To solve this issue, a fuzzy membership function can be used. From the membership value, the subject's stage can be predicted.

Based on the average hippocampal (left/right) size, three fuzzy sets are created namely $\mathrm{AD}, \mathrm{MCl}$, and $\mathrm{CN}$ for subjects of different aged groups. The combination of triangular and trapezoidal membership functions is used in this study. For the fuzzy sets AD, and CN, the trapezoidal membership function is used, whereas the triangular membership function is used for the fuzzy set $\mathrm{MCl}$. The mathematical expression for the triangular membership function is shown in equation 4.

$$
\mu_{m c i}(x)=\left\{\begin{array}{lr}
0, & \text { if } x \leq a \\
\frac{\mathrm{x}-\mathrm{a}}{\mathrm{m}-\mathrm{a}}, & \mathrm{a} \leq \mathrm{x} \leq \mathrm{m} \\
\frac{\mathrm{b}-\mathrm{x}}{\mathrm{b}-\mathrm{m}}, & \mathrm{m} \leq \mathrm{x} \leq \mathrm{b} \\
0, & \mathrm{x} \geq \mathrm{b}
\end{array}\right.
$$

Where, ' $a$ ' is the lower limit, ' $b$ ' is the upper limit, and ' $m$ ' is a value in lies in between a and $b$, for which the degree of the membership function is 1 (or 100\%), and $\mu_{M C l}(x)$ denotes the membership value for any input ' $\mathrm{x}$ ' in the fuzzy set 'MCl'.

The mathematical expression for the trapezoidal membership function can be expressed as equation 5. 


$$
\mu_{m c i}(x)=\left\{\begin{array}{lr}
0, & (x \leq a) \operatorname{or}(x \geq d) \\
\frac{\mathrm{x}-\mathrm{a}}{\mathrm{b}-\mathrm{a}}, & \mathrm{a} \leq \mathrm{x} \leq \mathrm{b} \\
1, & b \leq x \leq c \\
\frac{\mathrm{d}-\mathrm{x}}{\mathrm{d}-\mathrm{c}}, & \mathrm{c} \leq \mathrm{x} \leq \mathrm{d}
\end{array}\right.
$$

Where ' $a$ ' is the lower limit, 'd' is the upper limit, 'b' is the lower support limit, 'c' is the upper support limit such that $a<b<c<d$, and $\mu_{A D}(x)$ denotes the membership value for any input value ' $x$ ' in the fuzzy set 'AD'.

The fuzzy membership functions for the average hippocampus (left + right) size are shown graphically in figure 11 to figure 16 .

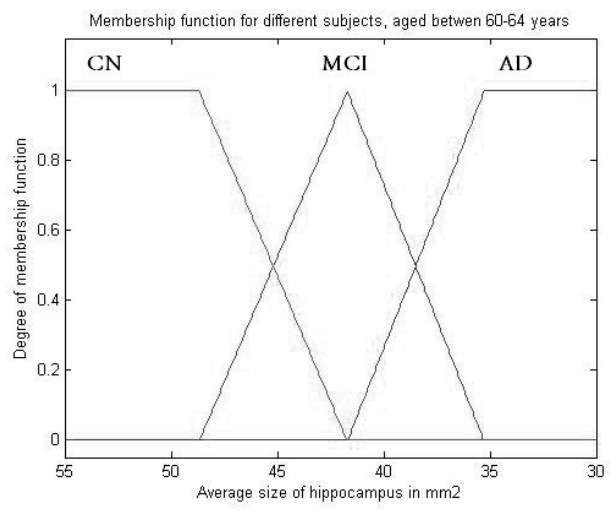

Figure 11. Degree of membership in fuzzy set $\mathrm{AD}, \mathrm{MCl}$, and $\mathrm{CN}$ for any subject (male/female) of aged between 60-64 years, based on their hippocampus (left/right) size

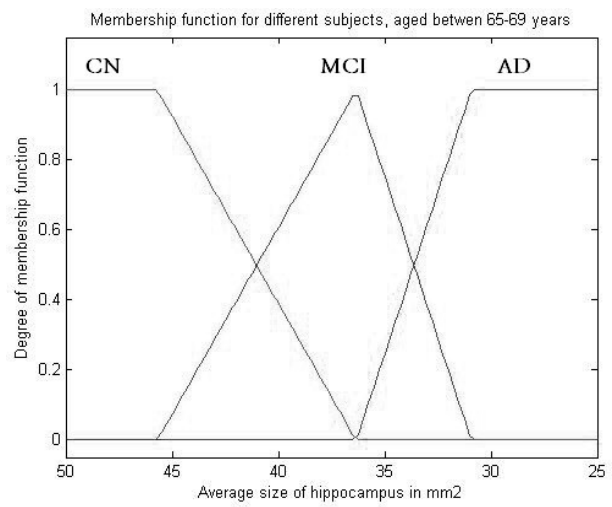

Figure 12. Degree of membership in fuzzy set $A D, M C l$, and $C N$ for any subject (male/female) of aged between 65-69 years, based on their hippocampus (left/right) size 


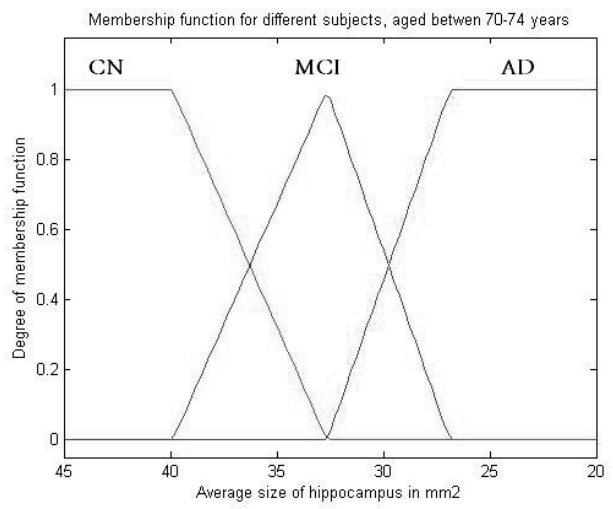

Figure 13. Degree of membership in fuzzy set $\mathrm{AD}, \mathrm{MCl}$, and $\mathrm{CN}$ for any subject (male/female) of aged between $70-74$ years, based on their hippocampus (left/right) size

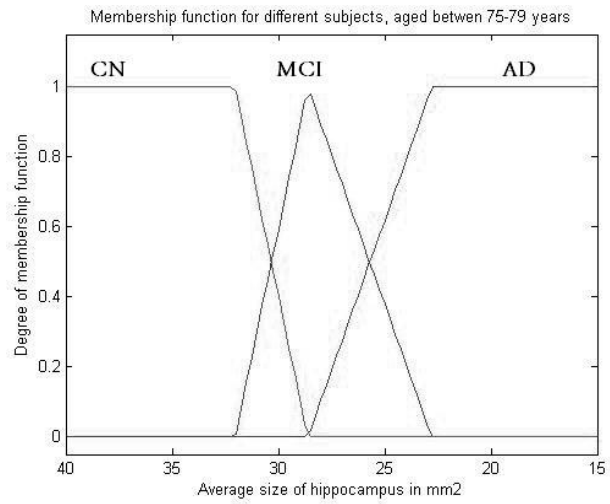

Figure 14. Degree of membership in fuzzy set $\mathrm{AD}, \mathrm{MCl}$, and $\mathrm{CN}$ for any subject (male/female) of aged between 75-79 years, based on their hippocampus (left/right) size

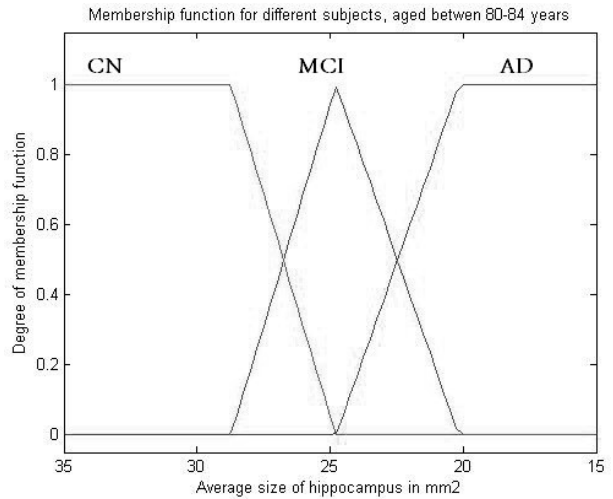

Figure 15. Degree of membership in fuzzy set $\mathrm{AD}, \mathrm{MCl}$, and $\mathrm{CN}$ for any subject (male/female) of aged between $80-84$ years, based on their hippocampus (left/right) size 


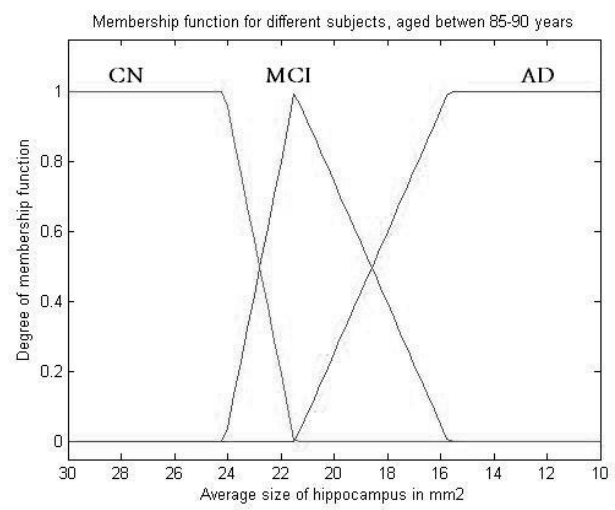

Figure 16. Degree of membership in fuzzy set $\mathrm{AD}, \mathrm{MCl}$, and $\mathrm{CN}$ for any subject (male/female) of aged between 85-90 years, based on their hippocampus (left/right) size

From figure 11 to figure 16, if a subject's age and hippocampal (left/right) size are known, the degree of membership in the fuzzy sets $\mathrm{CN}, \mathrm{MCl}$, and AD can be obtained. Based on the degree of membership value, it can be determined how much a subject belongs to a particular fuzzy set. If the membership value for a fuzzy set ' $A$ ' is found to be as 1 , then it implies that the subject is in the fuzzy set ' $A$ ' with $100 \%$ belongingness. If the membership value is 0 , then the subject will not be considered in the fuzzy set ' $A$ ', or the subject is said to be in the fuzzy set ' $A$ " with $0 \%$ belongingness. For any other membership value (between 0 and 1 ), the subject will be considered in the fuzzy set 'A' partially. From these 3 fuzzy sets, the dementia stage of any subject (CN/MCl/AD) can be predicted.

From the figure 11, it is found that a subject (male or female) ' $z$ ' aged in between 60-64 years can be included in fuzzy set CN with membership value 1 , if the size of its hippocampus (left + right) ' $h$ ' is more than or equals to $48.68101 \mathrm{~mm}^{2}$. Whereas the membership value of the subject is 0 , if ' $h$ ' is less than $41.71 \mathrm{~mm}^{2}$, and for any other value of ' $h$ ', the subject will be considered in the fuzzy set CN partially with any membership value in between 0 to 1 . Subject ' $z$ ' can be included in fuzzy set $\mathrm{MCl}$ with a degree of membership value as 1 if its ' $h$ ' is $41.71 \mathrm{~mm}^{2}$. The degree of membership function in $\mathrm{MCl}$ is 0 if ' $h$ ' is less than $35.29 \mathrm{~mm}^{2}$ and more than $48.67 \mathrm{~mm}^{2}$. The subject ' $z$ ' can be considered in fuzzy set AD with the degree of membership 1, if ' $h$ ' is less than or equals to $35.29 \mathrm{~mm}^{2}$, whereas the degree of the membership function is 0 if ' $h$ ' is greater than or equals to $41.70 \mathrm{~mm}^{2}$.

Similarly, from the figure 12, a subject ' $z 1$ ' aged in between 65-69 years is considered to be in fuzzy set $\mathrm{CN}$ with a degree of membership 1 if the size of the hippocampus (left + right) ' $\mathrm{h} 1$ ' is more than $45.70 \mathrm{~mm}^{2}$. If ' $\mathrm{h} 1$ ' is less than $36.35 \mathrm{~mm}^{2}$, then ' $\mathrm{z} 1$ ' can be included in $\mathrm{CN}$ with a degree of membership of 0 . Subject ' $z 1$ ' is said to be in fuzzy set $\mathrm{MCl}$ with membership value as 0 , if ' $\mathrm{h} 1$ ' is less than $30.93 \mathrm{~mm}^{2}$ and greater than $45.70 \mathrm{~mm}^{2}$, whereas the membership value is 1 if the value of ' $\mathrm{h} 1$ ' is $36.34 \mathrm{~mm}^{2}$. If ' $\mathrm{h} 1$ ' is smaller than $30.93 \mathrm{~mm}^{2}$, then ' $\mathrm{z} 1$ ' can be included in fuzzy set AD with a degree of membership value as 1 . If the value of ' $h 1$ ' is more than $36.33 \mathrm{~mm}^{2}$, then the membership value of ' $z 1$ ' in the fuzzy set AD is 0 .

From the figure 13, for a subject ' $z 2$ ' aged in between 70-74 years, if its hippocampus (left + right) size ' $\mathrm{h} 2$ ' is more than $39.90 \mathrm{~mm}^{2}$, then it can be considered that ' $\mathrm{z} 2$ ' is in the fuzzy set CN with a membership value of 1 . If ' $h 2$ ' is less than $32.64 \mathrm{~mm}^{2}$, then the membership value of ' $\mathrm{z} 2$ ' in fuzzy set $\mathrm{CN}$ is 0 . If ' $\mathrm{h} 2$ ' is determined as $32.64 \mathrm{~mm}^{2}$, then ' $\mathrm{z} 2$ ' can be included in the fuzzy set $\mathrm{MCl}$ with a membership value of 1 . For ' $h 2$ ' less than $26.88 \mathrm{~mm}^{2}$ and greater than $39.90 \mathrm{~mm}^{2}$, the membership value of ' $z 2$ ' in $\mathrm{MCl}$ is 0 . In the fuzzy set AD, ' $z 2$ ' can be included with a membership value of 1 if ' $h 2$ ' is less than $26.88 \mathrm{~mm}^{2}$. If ' $\mathrm{h} 2$ ' is more than $32.63 \mathrm{~mm}^{2}$, then the degree of membership value for ' $\mathrm{z} 2$ ' in $A D$ is 0.

From the figure 14, a subject ' $z 3$ ' of aged in between $75-79$ years can be included in the fuzzy set $\mathrm{CN}$ with a degree of membership value of 1 , if its hippocampus (left + right) size ' $h 3$ ' is more than $32.03 \mathrm{~mm}^{2}$. If the value of ' $\mathrm{h} 3$ ' is less than $28.63 \mathrm{~mm}^{2}$, then the degree of membership value of ' $\mathrm{h} 3$ ' in the fuzzy set CN is 0. For ' $z 3$ ', if ' $h 3$ ' is found to be as less than $22.79 \mathrm{~mm}^{2}$ and greater than 32.03 $\mathrm{mm}^{2}$, then its membership value in the fuzzy set $\mathrm{MCl}$ is 0 , whereas for ' $\mathrm{h} 3$ ' equals to $28.62 \mathrm{~mm}^{2}$, the degree of membership value in $\mathrm{MCl}$ is 1 . If the value of ' $\mathrm{h} 3$ ' is less than $22.79 \mathrm{~mm}^{2}$, then ' $\mathrm{z}$ ' can be included in the fuzzy set AD with a degree of membership value of 1 , whereas for any value of ' $h 3$ ' which is more than $28.61 \mathrm{~mm}^{2}$, the degree of membership of ' $z 3$ ' in AD is 0 . 
From the figure 15, if the hippocampus (left + right) size ' $h 4$ ' of a subject ' $z 4$ ' aged in between $80-84$ years is more than $28.72 \mathrm{~mm}^{2}$, then the membership value of the subject in the fuzzy set $\mathrm{CN}$ is 1 , whereas if the value of ' $h 4$ ' is below $24.79 \mathrm{~mm}^{2}$, then the membership value of ' $z 4$ ' in $\mathrm{CN}$ is 0 . If ' $\mathrm{h} 4$ ' equals to $24.78 \mathrm{~mm}^{2}$, then ' $\mathrm{z} 4$ ' is in the fuzzy set $\mathrm{MCl}$ with a degree of membership value 1 , whereas for ' $\mathrm{h} 4$ ' is less than $20.17 \mathrm{~mm}^{2}$ and more than $28.72 \mathrm{~mm}^{2}$, ' $\mathrm{z}$ ' ' is in the fuzzy set $\mathrm{MCl}$ with a degree of membership value of 0 . If ' $h 4$ ' is less than $20.17 \mathrm{~mm}^{2}$, then ' $z 4$ ' can be considered in the fuzzy set $A D$ with a membership value of 1 , whereas if ' $h 4$ ' exceeds $24.77 \mathrm{~mm}^{2}$, the degree of membership value in the fuzzy set $A D$ is 0 .

From the figure 16, it can be observed that, for a subject ' $z 5$ ' of aged in between 85-90 years, if its hippocampus (left + right) size ' $h 5$ ' is found to be as more than $24.10 \mathrm{~mm}^{2}$, then the subject can be included in the fuzzy set $\mathrm{CN}$ with a degree of membership value of 1 , whereas if ' $h 5$ ' is less than 21.49 $\mathrm{mm}^{2}$, then the degree of membership value for ' $\mathrm{z} 5$ ' in the fuzzy set $\mathrm{CN}$ is 0 . If the value of ' $\mathrm{z} 5$ ' equals to $21.48 \mathrm{~mm}^{2}$, then ' $z 5$ ' is considered in the fuzzy set $\mathrm{MCl}$ with a degree of membership value of 1 , whereas if ' $\mathrm{h} 5$ ' is less than $15.71 \mathrm{~mm}^{2}$ and more than $24.10 \mathrm{~mm}^{2}$, then the degree of membership value for ' $z 5$ ' in the fuzzy set $\mathrm{MCl}$ is 0 . For the subject ' $\mathrm{z} 5$ ', if ' $\mathrm{h} 5$ ' is less than $15.71 \mathrm{~mm}^{2}$, then the subject is considered in the fuzzy set $A D$ with a degree of membership value of 1 , whereas for the value of ' $h 5$ ' more than $21.47 \mathrm{~mm}^{2}$, the degree of membership value for ' $z 5$ ' in AD is 0 .

The hippocampal atrophy is observed separately for the left and right hippocampus, for male and female subjects, and for the subjects of different aged groups. Based on the hippocampal (left + right) atrophy value, we have created three more fuzzy sets namely, CNS, MCIS, and ADS separately. The fuzzy set CNS represents the $C N$ subjects, MCIS represents the $\mathrm{MCl}$ subjects, and ADS represents the AD subjects. The membership function of different subjects in the fuzzy sets CNS, MCIS, and ADS are shown in figure 17 to figure 22.

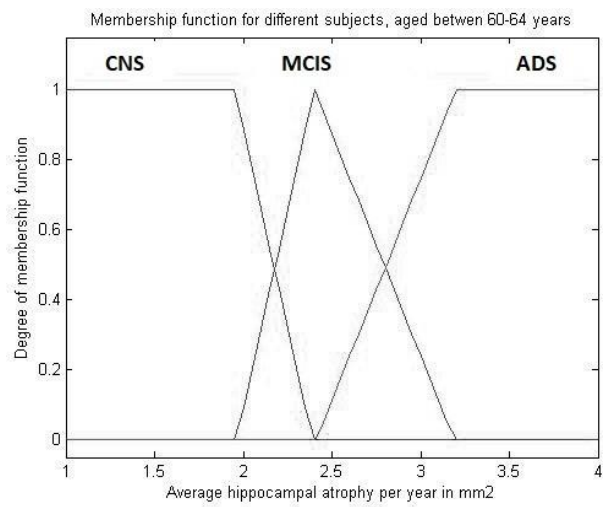

Figure 17. Degree of membership in fuzzy set ADS, MCIS, and CNS for any subject (male/female) of aged between 60-64 years, based on their hippocampus (left/right) atrophy per year

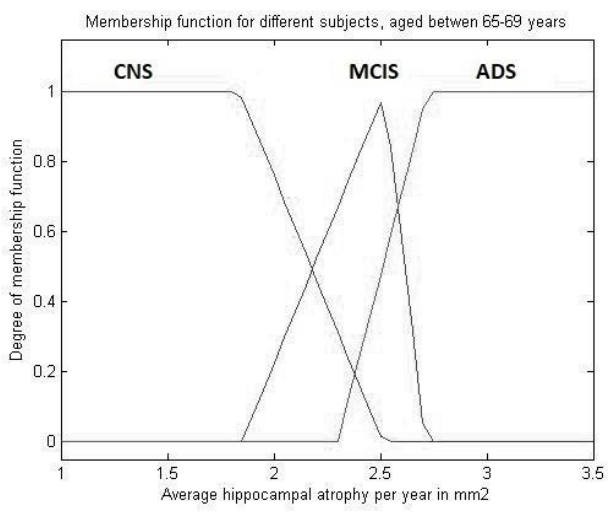

Figure 18. Degree of membership in fuzzy set ADS, MCIS, and CNS for any subject (male/female) of aged between 65-69 years, based on their hippocampus (left/right) atrophy per year 


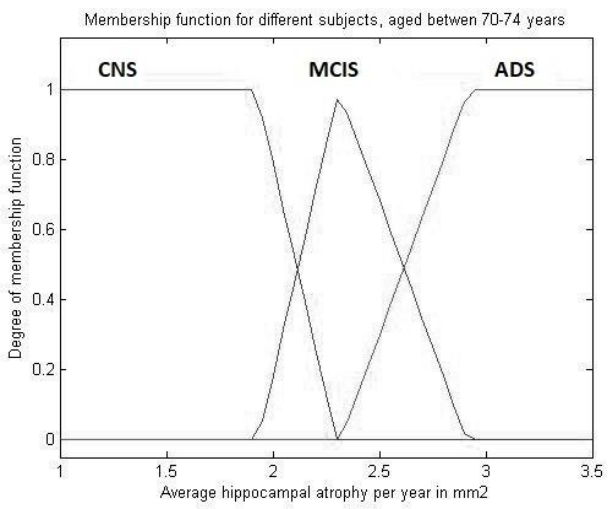

Figure 19. Degree of membership in fuzzy set ADS, MCIS, and CNS for any subject (male/female) of aged between 70-74 years, based on their hippocampus (left/right) atrophy per year

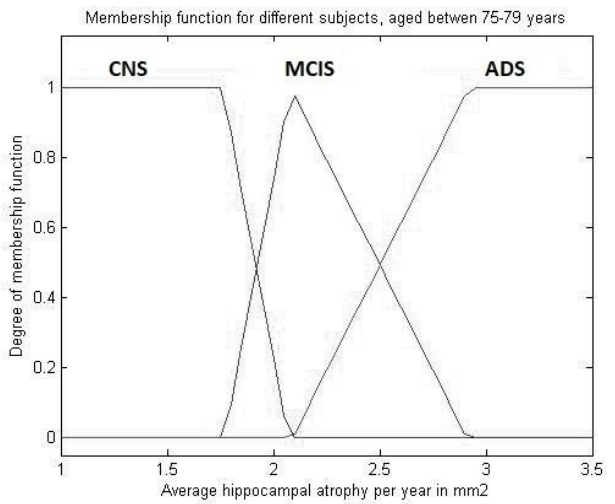

Figure 20. Degree of membership in fuzzy set ADS, MCIS, and CNS for any subject (male/female) of aged between 75-79 years, based on their hippocampus (left/right) atrophy per year

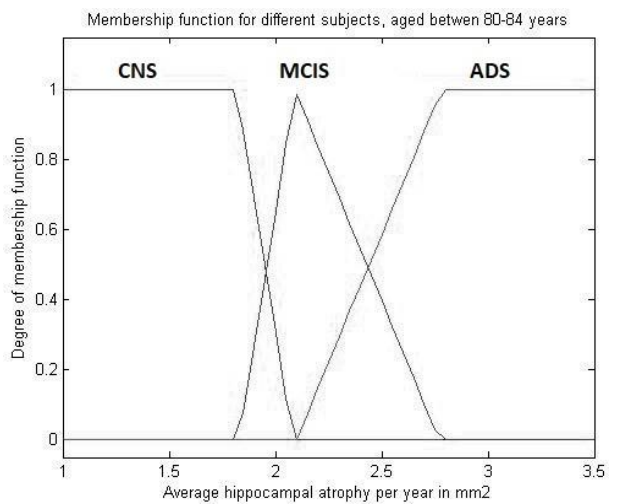

Figure 21. Degree of membership in fuzzy set ADS, MCIS, and CNS for any subject (male/female) of aged between 80-84 years, based on their hippocampus (left/right) atrophy per year 


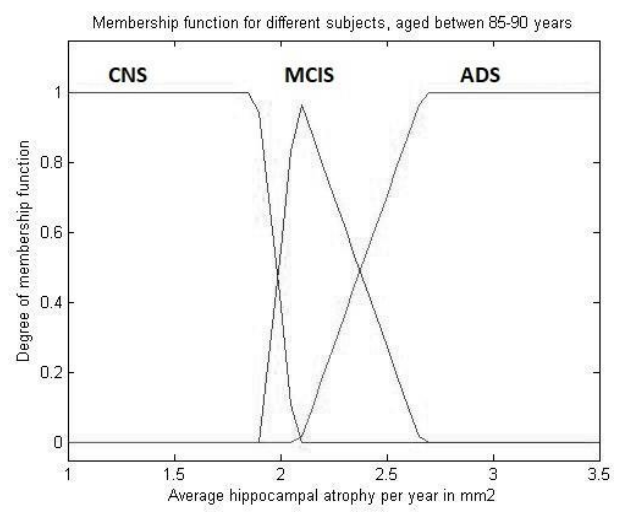

Figure 22. Degree of membership in fuzzy set ADS, MCIS, and CNS for any subject (male/female) of aged between 85-90 years, based on their hippocampus (left/right) atrophy per year

From the figure 17, it can be observed that a subject (male or female) ' $s$ ' aged in between 60-64 years can be included in fuzzy set CNS with membership value 1, if its average loss in hippocampus (left + right) size 'a' is less than or equals to $1.96 \mathrm{~mm}^{2}$ per year. Whereas the membership value of the subject is 0 , if ' $a$ ' is more than $2.39 \mathrm{~mm}^{2}$ per year, and for any other value of 'a', the subject will be considered in the fuzzy set CNS partially. Subject 's' can be included in fuzzy set MCIS with a degree of membership value as 1 , if its ' $a$ ' is $2.40 \mathrm{~mm}^{2}$ per year. The degree of membership function in MCIS is 0 if 'a' is less than $1.96 \mathrm{~mm}^{2}$ and more than $3.21 \mathrm{~mm}^{2}$. The subject ' $\mathrm{s}$ ' can be considered in fuzzy set ADS with a degree of membership 1, if 'a' is more than or equals to $3.20 \mathrm{~mm}^{2}$ per year, whereas the degree of the membership function is 0 if ' $a$ ' is less than or equals to $2.41 \mathrm{~mm}^{2}$ per year.

From the figure 18, a subject 's1' aged in between 65-69 years is considered to be in fuzzy set CNS with a degree of membership 1, if the hippocampal (left + right) atrophy rate per year 'a1' is less than $1.85 \mathrm{~mm}^{2}$. If 'a1' is more than $2.51 \mathrm{~mm}^{2}$, then ' $\mathrm{s} 1$ ' can be included in CNS with a degree of 0 . The subject ' $\mathrm{s} 1$ ' is said to be in fuzzy set MCIS with membership value of 0 , if 'a1' is less than $2.73 \mathrm{~mm}^{2}$ and greater than $1.85 \mathrm{~mm}^{2}$, whereas the membership value is 1 if the value of 'a1' is $2.52 \mathrm{~mm}^{2}$. If ' $a 1$ ' is more than $2.71 \mathrm{~mm}^{2}$, then ' $s 1$ ' can be included in fuzzy set ADS with the degree of membership value as 1. If the value of 'a1' is less than $2.53 \mathrm{~mm}^{2}$, then the membership value of ' $\mathrm{s} 1$ ' in the fuzzy set ADS is 0 .

From the figure 19, for a subject 's2' aged in between 70-74 years, if its hippocampus (left + right) size loss per year 'a2' is less than $1.93 \mathrm{~mm}^{2}$, then it can be considered that ' $\mathrm{s} 2$ ' is in the fuzzy set CNS with a membership value of 1 . If ' $a 2$ ' is more than $2.30 \mathrm{~mm}^{2}$, then the membership value of ' $\mathrm{s} 2$ ' in the fuzzy set CNS is 0 . If 'a2' is determined as $2.31 \mathrm{~mm}^{2}$, then 's2' can be included in fuzzy set MCIS with a membership value of 1 . For 'a2' more than $2.91 \mathrm{~mm}^{2}$ and less than $1.91 \mathrm{~mm}^{2}$, the membership value of 's2' in MCIS is 0 . In the fuzzy set ADS, 's2' can be included with a membership value of 1 , if 'a2' is more than $2.91 \mathrm{~mm}^{2}$. If 'a2' is less than $2.30 \mathrm{~mm}^{2}$, then the degree of membership value for 's2' in CNS is 0.

From the figure 20, a subject 's3' of aged in between 75-79 years can be included in the fuzzy set CNS with a degree of membership value of 1 , if its hippocampus (left + right) size loss per year 'a3' is less than $1.77 \mathrm{~mm}^{2}$. If the value of 'a3' is more than $2.07 \mathrm{~mm}^{2}$, then the degree of membership value of 's3' in the fuzzy set CNS is 0. For 's3', if 'a3' is found to be as more than $2.91 \mathrm{~mm}^{2}$ and less than $1.77 \mathrm{~mm}^{2}$, then its membership value in the fuzzy set MCIS is 0 , whereas for 'a3' equals to $2.08 \mathrm{~mm}^{2}$, the degree of membership value in MCIS is 1 . If the value of 'a3' is more than $2.91 \mathrm{~mm}^{2}$, then 's3' can be included in the fuzzy set ADS with a degree of membership value of 1, whereas for any value of 'a3' which is less than $2.09 \mathrm{~mm}^{2}$, the degree of membership of 'a3' in ADS is 0 .

From the figure 21, if the atrophy per year in hippocampus (left + right) size 'a4' of a subject '4' aged in between $80-84$ years is less than $1.83 \mathrm{~mm}^{2}$, then the membership value of the subject in the fuzzy set CNS is 1, whereas if the value of 'a4' exceeds $2.08 \mathrm{~mm}^{2}$, then the membership value of 'a4' 
in CNS is 0 . If 'a4' equals to $2.09 \mathrm{~mm}^{2}$, then ' $\mathrm{s} 4$ ' is in the fuzzy set MCIS with a degree of membership value 1, whereas for 'a4' less than $1.83 \mathrm{~mm}^{2}$ and more than $2.77 \mathrm{~mm}^{2}$, 's4' is in the fuzzy set MCIS with a degree of membership value of 0 . If 'a4' is more than $2.77 \mathrm{~mm}^{2}$, then 's4' can be considered in the fuzzy set ADS with a membership value of 1, whereas if 'a4' is below $2.10 \mathrm{~mm}^{2}$, the degree of membership value in the fuzzy set ADS is 0 .

From the figure 22, it can be observed that, for a subject 's5' of aged in between 85-90 years, if its hippocampus (left + right) size atrophy per year 'a5' is found to be as less than $1.90 \mathrm{~mm}^{2}$, then the subject can be included in the fuzzy set CNS with a degree of membership value of 1 , whereas if 'a5' is more than $2.07 \mathrm{~mm}^{2}$, then the degree of membership value for ' $\mathrm{s} 5$ ' in the fuzzy set CNS is 0 . If the value of ' $\mathrm{s} 5$ ' equals to $2.08 \mathrm{~mm}^{2}$, then ' $\mathrm{s} 5$ ' is considered to be in the fuzzy set MCIS with a degree of membership value of 1 , whereas if 'a5' is less than $1.90 \mathrm{~mm}^{2}$ and more than $2.66 \mathrm{~mm}^{2}$, then the degree of membership value for ' $\mathrm{s} 5$ ' in the fuzzy set $\mathrm{MCl}$ is 0 . For the subject ' $\mathrm{s} 5$ ', if 'a5' is less than $2.68 \mathrm{~mm}^{2}$, then the subject is considered in the fuzzy set ADS with a degree of membership value of 1 , whereas for the value of 'a5' which is less than $2.09 \mathrm{~mm}^{2}$, the degree of membership value for ' $\mathrm{s} 5$ ' in ADS is 0.

\section{CONCLUDING REMARKS}

The average size of the hippocampus in the brain is studied using MATLAB tool for three subject groups namely $\mathrm{CN}, \mathrm{MCl}$, and $\mathrm{AD}$ with an adequate number of $\mathrm{MR}$ images for both males and females separately. The age group of the subjects further categorizes the study. From the study, it is found that the average size of the hippocampus in the brain (both left and right hippocampus) is declined over the age in the order of $\mathrm{AD}>\mathrm{MCl}>\mathrm{CN}$ subjects, hence the average size of the hippocampus is in the order of $\mathrm{CN}>\mathrm{MCl}>\mathrm{AD}$ subjects. It is found that the average atrophy per year for the $\mathrm{CN}$ subjects is approximately $1.10 \%$. For the $\mathrm{MCl}$ subjects, it is nearly $2.33 \%$, and for the AD subjects, the atrophy per year is approximately $4.62 \%$. From the study, it is also observed that the difference in the size of the hippocampus between $\mathrm{CN}$ and $\mathrm{MCl}$ subjects is approximately $17.05 \%$, whereas this difference between $\mathrm{CN}$ and $\mathrm{AD}$ subjects is nearly $31.90 \%$, and between $\mathrm{MCl}$ and $\mathrm{AD}$ subjects is $18.24 \%$.

\section{CONFLICT OF INTEREST}

The authors declare no potential conflict of interest.

\section{ACKNOWLEDGEMENT}

The authors sincerely acknowledge the help and support provided by Dr. Donboklang Lynser, Assistant Professor, Radiology Department, North Eastern Indira Gandhi Regional Institute of Health and Medical Sciences (NEIGRIHMS), Shillong, India, for validating data and the research work.

\section{REFERENCES}

[1] Korolev IO. Alzheimer's disease: a clinical and basic science review. Medical Student Research Journal, 2014. 4(1):24-33.

[2] Vyhnálek, M., Marková, H., Laczó, J., De Beni, R., \& Di Nuovo, S. (2019). Assessment of Memory Impairment in Early Diagnosis of Alzheimer's Disease. Current Alzheimer Research, 16(11), 975-985. doi: 10.2174/1567205016666191113125303

[3] NIH. Alzheimer's disease: a clinical and basic science review. https://www.nia.nih.gov/health/ alzheimers-disease-fact-sheet. Accessed: 2020-07-13.

[4] A Association. Alzheimer's Disease Fact

Sheet. https://www.alz.org/in/ dementia-alzheimers-en.asp\#diagnosis. Accessed: 2020-07-13.

[5] Sun Z, van de Giessen M, Lelieveldt BP, Staring M. Detection of conversion from mild cognitive impair- ment to Alzheimer's disease using longitudinal brain MRI. Frontiers in Neuroinformatics, 2017. 11:16. doi:10.3389/fninf.2017.00016.

[6] Martinez-Torteya, A., Gomez-Rueda, H., Trevino, V., Farber, J., Tamez-Pena, J., \& Alzheimer's Disease Neuroimaging Initiative. (2018). Identification and temporal characterization of features associated with the conversion from mild cognitive impairment to Alzheimer's disease. Current Alzheimer Research, 15(8), 751-763. 
[7] Albert MS, DeKosky ST, Dickson D, Dubois B, Feldman HH, Fox NC, Gamst A, Holtzman DM, Jagust WJ, Petersen RC, et al. The diagnosis of mild cognitive impairment due to Alzheimer's disease: rec- ommendations from the National Institute on Aging-Alzheimer's Association workgroups on diagnostic guidelines for Alzheimer's disease. Focus, 2013. 11(1):96-106. doi:10.1016/j.jalz.2011.03.008.

[8] Davis, M., O'Connell, T., Johnson, S., Cline, S., Merikle, E., Martenyi, F., \& Simpson, K. (2018). Estimating Alzheimer's disease progression rates from Normal cognition through mild cognitive impairment and stages of dementia. Current Alzheimer Research, 15(8), 777-788.

[9] Halliday G. Pathology and hippocampal atrophy in Alzheimer's disease. The Lancet Neurology, 2017. 16(11):862-864. doi:10.1212/01.wnl.0000344568.09360.31.

[10] Anand KS, Dhikav V. Hippocampus in health and disease: An overview. Annals of Indian Academy of Neurology, $2012.15(4): 239$. doi:10.4103/0972-2327.104323.

[11] Bright P, Buckman J, Fradera A, Yoshimasu H, Colchester AC, Kopelman MD. Retrograde amnesia in patients with hippocampal, medial temporal, temporal lobe, or frontal pathology. Learning \& Memory, 2006. 13(5):545-557. doi:10.1101/Im.265906.

[12] Jack CR, Petersen RC, O'Brien PC, Tangalos EG. MR-based hippocampal volumetry in the diagnosis of Alzheimer's disease. Neurology, 1992. 42(1):183-183. doi:10.1212/wnl.42.1.183.

[13] Jack CR, Petersen RC, Xu Y, O'brien P, Smith GE, Ivnik RJ, Boeve BF, Tangalos EG, Kokmen E. Rates of hippocampal atrophy correlate with change in clinical status in aging and AD. Neurology, 2000. 55(4):484-490. doi:10.1212/wnl.55.4.484.

[14] Colliot O, Che telat G, Chupin M, Desgranges B, Magnin B, Benali H, Dubois B, Garnero L, Eustache F, Lehe 'ricy S. Discrimination between Alzheimer disease, mild cognitive impairment, and normal aging by using automated segmentation of the hippocampus. Radiology, 2008. 248(1):194-201. doi:10.1148/ radiol.2481070876.

[15] Mega MS, Small GW, Xu ML, Felix J, Manese M, Tran NP, Dailey Jl, Ercoli LM, Bookheimer SY, Toga AW. Hippocampal atrophy in persons with age-associated memory impairment: volumetry within a com- mon space. Psychosomatic Medicine, 2002. 64(3):487-492. doi:10.1097/00006842-200205000-00013.

[16] Apostolova LG, Dutton RA, Dinov ID, Hayashi KM, Toga AW, Cummings JL, Thompson PM. Conversion of mild cognitive impairment to Alzheimer disease predicted by hippocampal atrophy maps. Archives of neurology, 2006. 63(5):693-699. doi:10.1001/archneur.63.5.693.

[17] Barnes J, Bartlett JW, van de Pol LA, Loy CT, Scahill RI, Frost C, Thompson P, Fox NC. A meta-analysis of hippocampal atrophy rates in Alzheimer's disease. Neurobiology of aging, 2009. 30(11):1711-1723. doi:10.1016/j.neurobiolaging.2008.01.010.

[18] Tabatabaei-Jafari H, Shaw ME, Cherbuin N. Cerebral atrophy in mild cognitive impairment: a systematic review with meta-analysis. Alzheimer's \& Dementia: Diagnosis, Assessment \& Disease Monitoring, 2015. 1(4):487-504. doi:10.1016/j.dadm.2015.11.002.

[19] Brueggen, K., Dyrba, M., Kilimann, I., Henf, J., Hoffmann, W., Thyrian, J. R., \& Teipel, S. (2018). Hippocampal Mean Diffusivity for the Diagnosis of Dementia and Mild Cognitive Impairment in Primary Care. Current Alzheimer Research, 15(11), 1005-1012. doi: 10.2174/1567205015666180613114829

[20] Henneman W, Sluimer J, Barnes J, Van Der Flier W, Sluimer I, Fox N, Scheltens P, Vrenken H, Barkhof F. Hippocampal atrophy rates in Alzheimer disease: added value over whole brain volume measures. Neurology, $2009.272(11): 999-1007$. Doi:10.1212/01.wnl.0000344568.09360.31.

[21] Seab J, Jagust W, Wong S, Roos M, Reed BR, Budinger T. Quantitative NMR measurements of hip- pocampal atrophy in Alzheimer's disease. Magnetic resonance in medicine, 1988. 8(2):200-208. doi: 10.1002/mrm.1910080210.

[22] Liedes H, Lo“tjo“nen J, Kortelainen JM, Novak G, van Gils M, Gordon MF, Initiative ADN, et al. Multivari- ate Prediction of Hippocampal Atrophy in Alzheimer's Disease. Journal of Alzheimer's Disease, 2019. 68(4):1453-1468. doi:10.3233/JAD-180484.

[23] Uysal G, Ozturk M. Hippocampal atrophy based Alzheimer's disease diagnosis via machine learning methods. Journal of Neuroscience Methods, 2020. p. 108669. doi:10.1016/j.jneumeth.2020.108669.

[24] Mueller SG, Schuff N, Yaffe K, Madison C, Miller B, Weiner MW. Hippocampal atrophy patterns in mild cognitive impairment and Alzheimer's disease. Human brain mapping, 2010. 31(9):1339-1347. doi:10.1002/hbm.20934.

[25] Wang, D., Guo, Z. H., Liu, X. H., Li, Y. H., \& Wang, H. (2015). Examination of hippocampal differences between Alzheimer disease, amnestic mild cognitive impairment and normal aging: diffusion kurtosis. Current Alzheimer Research, $12(1), 80-87$.

[26] Despotovic 'I, Goossens B, Philips W. MRI segmentation of the human brain: challenges, methods, and applications. Computational and mathematical methods in medicine, 2015. 2015. doi:10.1155/2015/450341.

[27] Zhuang, A. H., Valentino, D. J., \& Toga, A. W. (2006). Skull-stripping magnetic resonance brain images using a model-based level set. Neurolmage, 32(1), 79-92.

[28] Kalavathi P, Prasath VS. Methods on skull stripping of MRI head scan images-a review. Journal of digital imaging, 2016. 29(3):365379. doi:10.1007/s10278-015-9847-8.

[29] Khwairakpam A, Hazarika RA, Kandar D. Image Segmentation by Fuzzy Edge Detection and Region Growing Technique. In: Proceedings of the Third International Conference on Microelectronics, Comput- ing and Communication Systems. Springer, 2019 pp. $51-64$.

[30] Bala A, Sharma AK. Split and merge: A region based image segmentation. Int. J. Emerg. Res. Manage. Technol., $2017.6(8): 306-309$. doi:10.23956/IJERMT.V6I8.157.

[31] Panwar P, Gopal G, Kumar R. Image Segmentation using K-means clustering and Thresholding. Image, 2016. 3(05):1787-1793.

[32] Raju PDR, Neelima G. Image segmentation by using histogram thresholding. International Journal of Computer Science Engineering and Technology, 2012. 2(1):776-779.

[33] Bhoyar K, Kakde O. Colour image segmentation using fast fuzzy c-means algorithm. ELCVIA: electronic letters on computer vision and image analysis, 2010. pp. 18-31. doi:10.5565/rev/elcvia.361.

[34] Hazarika RA, Kharkongor K, Sanyal S, Maji AK. A Comparative Study on Different Skull Stripping Tech- niques from Brain Magnetic Resonance Imaging. In: International Conference on Innovative Computing and Communications. Springer, 2020 pp. $279-288$.

[35] Haralick, R. M., \& Shapiro, L. G. (1985). Image segmentation techniques. Computer vision, graphics, and image processing, 29(1), 100 132

[36] Amoroso N, La Rocca M, Bellotti R, Fanizzi A, Monaco A, Tangaro S, Initiative ADN, et al. Alzheimer's disease diagnosis based on the hippocampal unified multi-atlas network (HUMAN) algorithm. Biomedical engineering online, 2018. 17(1):6. doi:10.1186/s12938-018 0439-y.

[37] van der Lijn, F., Den Heijer, T., Breteler, M. M., \& Niessen, W. J. (2008). Hippocampus segmentation in MR images using atlas registration, voxel classification, and graph cuts. Neuroimage, 43(4), 708-720.

[38] Shi Y, Cheng K, Liu Z. Hippocampal subfields segmentation in brain MR images using generative adver- sarial networks. Biomedical engineering online, 2019. 18(1):1-12. doi:10.1186/s12938-019-0623-8.

[39] Sele tchi ED, et al. Medical image processing using MATLAB. Journal of Information Systems \& Opera- tions Management, 2008. 2(1):194-210.

[40] Pluta J, Mueller S, Craige C, Yushkevich P. Hippocampal subfield segmentation protocol at 4T. 